\title{
Wavefront-guided refractive surgery results of training-surgeons
}

\author{
Resultados das cirurgias refrativas guiadas por frentes de ondas de cirurgiões em treinamento
}

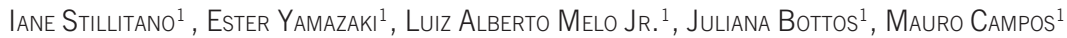

\begin{abstract}
Purpose: To assess clinical outcomes and changes on higher-order aberrations $(\mathrm{HOA})$ after wavefront-guided laser in situ keratomileusis (LASIK) and photorefractive keratectomy (PRK) for correction of myopia and myopic astigmatism performed by training-surgeons.

Methods: One hundred and seventy patients had customized LASIK (207 eyes) and PRK (103 eyes) performed by surgeons in-training using the LADARVision 4000 (Alcon, Fort Worth, TX). Preoperative and 1, 3,6 and 12 months postoperative data of spherical equivalent (SE), best spectacle-corrected visual acuity (BSCVA) and uncorrected visual acuity (UCVA) were analysed. Wavefront changes were determined using the LADARWave HartmannShack wavefront aberrometer and the pupil size was scaled for $6.5 \mathrm{~mm}$

Results: The mean SE in the LASIK group was $-3.04 \pm 1.07 \mathrm{D}$ and in the PRK group was -1.60 \pm 0.59 D. At 1-year follow-up, (80.6\%) (LASIK) and (66.7\%) (PRK) were within $\pm 0.50 \mathrm{D}$ of the intended refraction. The UCVA was $20 / 20$ or better in (58.1\%) (LASIK) and (66.7\%) (PRK) of the operated eyes. A statistically significant positive correlation was found between achieved versus attempted refractive correction in both groups: $L A S I K(r=0.975, P<0.0005)$ and PRK $(r=0.943$ $\mathrm{P}<0.005)$. The higher-order aberrations ( $\mathrm{HO}) \mathrm{RMS}$ and coma did not changed signicantly in the PRK group between preoperative and 1-year follow-up. In the LASIK group the HO RMS and coma changed between preoperative and 1-month postoperative but remained statistically unchanged during 1-year follow-up. The spherical aberration showed statistically significant changes in both groups.
\end{abstract}

Conclusions: Wavefront-guided LASIK and photorefractive keratectomy performed by training-surgeons were found to be similarly effective, predictable and stable.

Keywords: Keratomileusis, laser in situ; Photorefractive keratectomy/methods; Myopia/surgery; Astigmatism/surgery; Laser, excimer; Refraction, ocular; Refractive surgical procedures; Visual acuity; Ophthalmology/education

\section{RESUMO}

Objetivo: Avaliar os resultados clínicos e mudanças nas aberrações de altaordem (HOA), após ceratomileuse assistida por excimer laser in situ (LASIK) ceratectomia fotorrefrativa (PRK) guiados por frentes de onda para correção da miopia e astigmatismo miópico realizada por cirurgiões em treinamento. Métodos: Estudo prospectivo de 170 pacientes submetidos a LASIK personalizado (207 olhos) e PRK (103 olhos) realizados por cirurgiões em treinamento utilizando o LADARVision 4000 (Alcon, Fort Worth, TX). Dados do equivalente esférico (SE), melhor acuidade visual corrigida (BSCVA) e acuidade visual não corrigida (UCVA) foram analisados no pré-operatório e com 1, 3, 6 e 12 meses de pós-operatório. As alterações de frentes de onda foram determinadas usando o aberrômetro Hartmann-Shack (LADARWave)e o tamanho da pupila foi determinado para 6,5 $\mathrm{mm}$.

Resultados: A média do SE no grupo de LASIK foi-3,04 \pm 1,07 D e no grupo de PRK foi -1,60 $\pm 0,59 D$. No seguimento de um ano, (80,6\%) (LASIK) e (66,7\%) (PRK) estavam dentro de $\pm 0,50$ D de equivalente esférico. A UCVA foi de 20/20, ou melhor, em (58,1\%) (LASIK) e (66,7\%) (PRK) dos olhos operados. Foi encontrada correlação positiva estatisticamente significante entre correção refrativa alcançada versus pretendida em ambos os grupos: LASIK $(r=0,975, P<0,0005)$ e $P R K(r=0,943, P<0,005)$. O HO RMS e coma não alteraram significantemente no grupo PRK entre pré-operatório e após um ano de seguimento. No grupo de LASIK o HO RMS e o coma alteraram entre pré-operatório e $1^{\circ}$ mês de pósoperatório, mas permaneceram estatisticamente inalterados durante um ano de seguimento. Houve alterações estatisticamente significantes da aberração esférica em ambos os grupos.

Conclusões: OLASIK eo PRK guiados porfrentes de onda, realizados por cirurgiões em treinamento, mostraram ser similarmente eficazes, previsíveis e estáveis.

Descritores: Ceratomileuse assistida por excimer laser in situ; Ceratectomia fotorrefrativa/métodos; Miopia/Cirurgia; Astigmatismo/cirurgia; Lasers de excimer; Refração ocular; Procedimentos cirurgicos refrativos; Acuidade visual; Oftalmologia/educação

\section{INTRODUCTION}

A s refractive surgery has become widespread, its investigation has increasing efforts to develop more sofisticated technicques for correcting visual errors. The modern surgery is heading toward wavefront-guided customized

\footnotetext{
Study carried out at Ophthalmology Department, Escola Paulista de Medicina, Universidade Federal de São Paulo - UNIFESP - São Paulo (SP), Brazil.

Physician, Ophthalmology Department, Escola Paulista de Medicina, Universidade Federal de São Paulo - UNIFESP - São Paulo (SP), Brazil.

Correspondence address: lane Stillitano, MD. Rua Botucatu, 822 - São Paulo (SP) CEP 04023-062 - E-mail: ianestillitano@oftalmo.epm.br

Recebido para publicação em 28.02.2008

Última versão recebida em 07.04.2010

Aprovação em 26.07.2010

Nota Editorial: Depois de concluída a análise do artigo sob sigilo editorial e com a anuência do Dr. Paulo Gilberto Jorge Fadel sobre a divulgação de seu nome como revisor, agradecemos sua participação neste processo.
}

ablation with the aim of treating not only lower-order aberrations, but also individual higher-order aberrations ${ }^{(1-3)}$

The effectiveness, predictability, stability and safety of wavefront-guided laser in situ keratomileusis (LASIK) and photorefractive keratectomy (PRK) for low and moderate myopia have been widely reported. However, there is evidence to support that both procedures may change higher-order aberrations ${ }^{(4-10)}$.

With an estimated 1.5 million annual refractive surgeries performed worldwide, fellowship programs have increased exposure to this procedure over the past few years ${ }^{(11)}$. The Refractive Surgery Survey 2004 showed that wavefront-guided ablation increased (71.6\%) more than the year before ${ }^{(12)}$

Is there a long-term difference between lamellar ablation and surface ablation in customized myopic treatments performed by surgeons-in-training? There are few data about standard refractive surgery performed by less experienced surgeons and up to now there are no reports related to learning curve in customized ablation. 
The purpose of our study was to assess clinical outcomes and changes of higher-order aberrations ( $\mathrm{HOA}$ ) after wavefrontguided Laser in Situ Keratomileusis (LASIK) and Photorefractive Keratectomy performed by refractive fellows-in-training.

\section{METHODS}

\section{Study design AND PATIENT SELECtion}

This research was undertaken at the Refractive Surgery Sector of Vision Institute of Federal University of São Paulo (UNIFESP) Brazil.

A prospective nonrandomized study from January 2004 through March 2005 comprised 310 eyes of 170 patients who had customized LASIK (207 eyes) and PRK (103 eyes) was performed by 10 surgeons in-training, whom were assisted by an experienced refractive surgeon present at all times, in the context of a structured fellowship program.

The study was approved by the Ethical Committee of UNIFESP. Informed Consent was obtained from all patients after through explanation of the procedure and its potential benefits and risks. Inclusion criteria included a myopic spherical equivalent of less than $-12.00 \mathrm{D}$ and at least 2 postoperative followup visits. All patients were refractive surgery candidates for myopia and myopic astigmatism and postsurgical emmetropia was intended in all cases.

The exclusion criteria included severe dry eye, clinical or topographic evidence of keratoconus, previous ocular surgery, systemic diseases or therapy that might influence corneal wound healing. After performing laser surgery the cases that required retreatment were also excluded.

Preoperatively, all patients had a complete ophthalmic examination that correspond to the refractive sector routine including the determination of manifest and cycloplegic refraction, uncorrected visual acuity (UCVA) and best spectacle-corrected visual acuity (BSCVA) measured using Snellen acuity charts. Also, pupillometry, applanation tonometry, biomicroscopy, fundoscopy, corneal topography, ultrassound and optical pachymetry (ORBSCAN) and ocular wavefront aberration measurement were performed.

Eyes were divided into 2 groups based on the surgical technicque: LASIK (group 1) and PRK (group 2).

In the LASIK group two types of microkeratomes were used to create a superior hinge flap: Hansatome (Bausch \& Lomb) and Moria (Carriazo Barraquer). Surgeons used the Hansatome with a 160 or $180 \mu \mathrm{m}$ deph plate (65 eyes) and Moria was used with a $160 \mu \mathrm{m}$ plate (142 eyes). In PRK procedure the epithelium was debrided mecanically using a blunt spatula.

Prior to performing any procedure, the fellows-surgeons were required to practice with each microkeratome on wet lab using animal eyes. Appropriate management of each complication was discussed with the attending surgeon.

The procedures were performed with the LADARVision 4000 (Alcon, Fort Worth, TX). The optical zone was 6.5 mm, with additional 1.25 transition zone in all cases. The LADARVision ${ }^{\text {TM }}$ system uses a $0.8 \mathrm{~mm}, 60 \mathrm{~Hz}$ flying scanning spot with nonsequential pulse placement. LADAR system uses a laser-based tracking system that operates in a frequency of $4000 \mathrm{~Hz}$.

Postoperative management of group 1 included administration of one drop four times daily (q.i.d) of ciprofloxacin cloridrate and dexametasone (1\%) for 2 weeks and a lubricant eyedrop during at least 3 months; group 2 a bandage soft contact lens was applied immediately after surgery maintained until complete epithelial healing, one drop q.i.d of fluormetolone $0.1 \%$ for 24 hour, one drop q.i.d of ciprofloxacin, and a artificial tears during at least 3 months until reepithiled.
Postoperative evaluation occurred at 1, 3, 6 month and 1-year follow-up. Manifest and cycloplegic refraction, UCVA, BSCVA, biomicroscopy, corneal topography and ocular wavefront aberration measurement were evaluated.

Wavefront changes of HOA were determined for pupil size of $6.5 \mathrm{~mm}$ with the LADARWave Shack-Hartmann wavefront aberrometer, this device measures spherocylindrical refractive errors (defocus and astigmatism) and higher-order aberrations.

Data on UCVA, BSCVA, spherical equivalent (SE), higher-order aberrations (HOA) root mean square (RMS), spherical aberration, total coma, vertical coma and horizontal coma were collected before and after surgery in both groups.

\section{Data analysis and statistical methods}

Data of clinical outcomes, linear regression and astigmatism vector analysis were registered at the Refractive Surgery Consultant ${ }^{\mathrm{TM}}$ Elite database software for analysis and calculated as means and standard deviations or frequencies. Linear regression was used for evaluation of the relationship between intended and achieved correction by Pearson's correlation coefficient (R) and regression coefficient (b) with a confidence interval of $1.00 \mathrm{D}$.

Vector analysis was used to represent a surgically induced refractive change (SIRC) by doubled angle plots that provide a useful means to visually evaluate cylinder outcomes. They are created for determining cylinder values to avoid having axis shifts misrepresent astigmatic changes.

Student's unpaired t-test was used to evaluate the differences between the two groups for baseline values and for postoperative (1 mo, $3 \mathrm{mo}, 6 \mathrm{mo}$ and 1yr) variation values. The t-test for paired data was used to evaluate variations between peoperative and postoperative values for visual and aberration parameters. A P value less than 0.05 was regarded as statistically significant. This statistical analyses was performed using SPSS Advanced Statistical 7.5 Software (Chicago, IL, 1997).

\section{RESULTS}

The mean age of patients undergoing LASIK was 31 years (range 21 to 53 years) and (53.6\%) were female. The mean age of patients undergoing PRK was 32 years (range 21 to 51 years) and $(58 \%)$ were female.

The mean SE refraction in the LASIK group was $-3.04 \pm 1.07 \mathrm{D}$ (range $-0.13 \mathrm{D}$ to $-6.46 \mathrm{D}$ ) and in the PRK group was $-1.60 \pm 0.59 \mathrm{D}$ (range -0.25 to -2.90 ). The mean programmed cylinder correction was $-0.52 \pm 0.47 \mathrm{D}$ (range -0.10 to -2.58 ) in the LASIK eyes and $-0.45 \pm 0.38 \mathrm{D}$ (range 0 to $-1.37 \mathrm{D}$ ) in the PRK eyes.

At 1-year postoperatively, (80.6\%) in the LASIK group and $(66.7 \%)$ in the PRK group were within $\pm 0.50 \mathrm{D}$ of intended refraction (Table 1). The UCVA was $20 / 20$ or better in (58.1\%) and $20 / 30$ or better in (100\%) of LASIK eyes. The UCVA was 20/20 or better in (66.7\%) and 20/30 or better in (87.5\%) of PRK eyes. In both groups no eye lost $\geq 2$ lines of BSCVA, (12.5\%) in in the PRK group and (3.2\%) in the LASIK group gained 1 or more lines of BSCVA.

The mean residual SE refraction was $+0.24 \pm 0.45 \mathrm{D}$ in the LASIK eyes and $+0.23 \pm 0.54 \mathrm{D}$ in the PRK eyes. The mean residual cylinder was $-0.28 \pm 0.30 \mathrm{D}$ (range 0 to $-1.02 \mathrm{D}$ ) in the LASIK group and $-0.10 \pm 0.18 \mathrm{D}$ (range 0 to $-0.51 \mathrm{D}$ ) in the PRK group. The mean induced astigmatism at 1-year follow-up was: $0.68 \pm 0.44 \mathrm{D}$ in the LASIK eyes and $0.49 \pm 0.45 \mathrm{D}$ in the PRK eyes (Figure 1). There was no statistically significant surgically induced astigmatism (SIA) by magnitude or by axis.

The incidence of eyes requering retreatment was (1.75\%) (10 of 320 eyes).

A statistically significant and moderately positive correlation was found between achieved versus attempted sphero- 
Table 1. Predictability of wavefront-guided LASIK and PRK during 1, 3, 6 months and 1 year-follow-up

\begin{tabular}{|c|c|c|c|c|c|c|c|c|}
\hline \multirow{3}{*}{$\begin{array}{l}\text { Refractive } \\
\text { outcomes }\end{array}$} & \multicolumn{6}{|c|}{ Number of eyes (\%) } & & \\
\hline & \multicolumn{2}{|c|}{1 month } & \multicolumn{2}{|c|}{3 months } & \multicolumn{2}{|c|}{6 months } & \multicolumn{2}{|c|}{1 year } \\
\hline & LASIK & PRK & LASIK & PRK & LASIK & PRK & LASIK & PRK \\
\hline \pm 0.5 & $116(71.2)$ & $62(76.5)$ & $92(80.0)$ & $40(59.7)$ & $61(84.7)$ & $45(78.9)$ & $25(80.6)$ & $16(66.7)$ \\
\hline \pm 1.0 & $151(92.6)$ & 78 (96.3) & $106(92.2)$ & $63(94.0)$ & $70(97.2)$ & 54 (94.7) & 29 (93.5) & $23(95.8)$ \\
\hline$<-1.0$ & $1(0.6)$ & $0(0.0)$ & $2(1.7)$ & $0(0.0)$ & $0(0.0)$ & $0(0.0)$ & $0(0.0)$ & $0(0.0)$ \\
\hline$<+1.0$ & 11 ( 6.7) & $3(3.7)$ & $7(6.1)$ & $4(6.0)$ & $2(2.8)$ & $3(5.3)$ & $2(6.5)$ & $1(4.2)$ \\
\hline
\end{tabular}

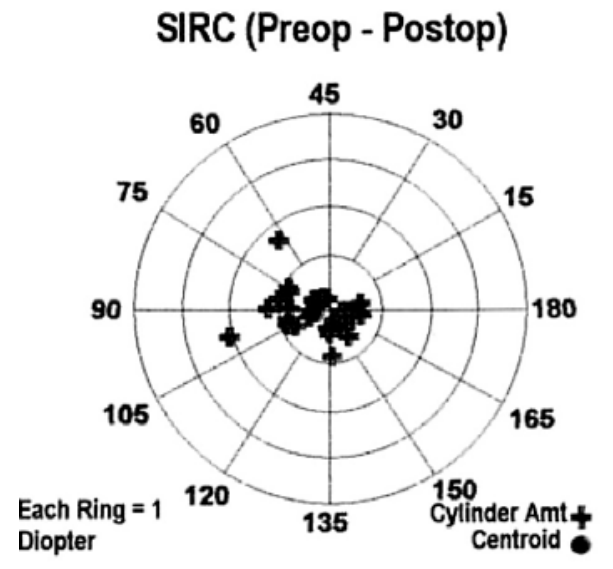

Centroid $=0.32 D$ Axis 96 Degrees

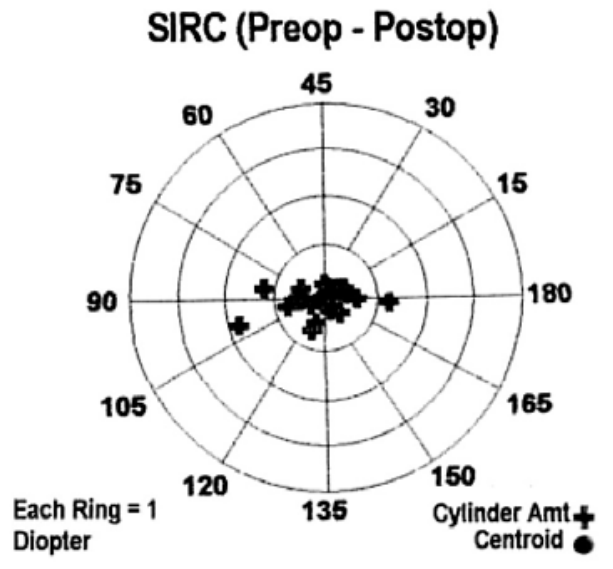

Centroid $=0.13 D$ Axis 104 Degrees

Figure 1. Double angle plot analysis of induced astigmatism: LASIK (right) and PRK (left).
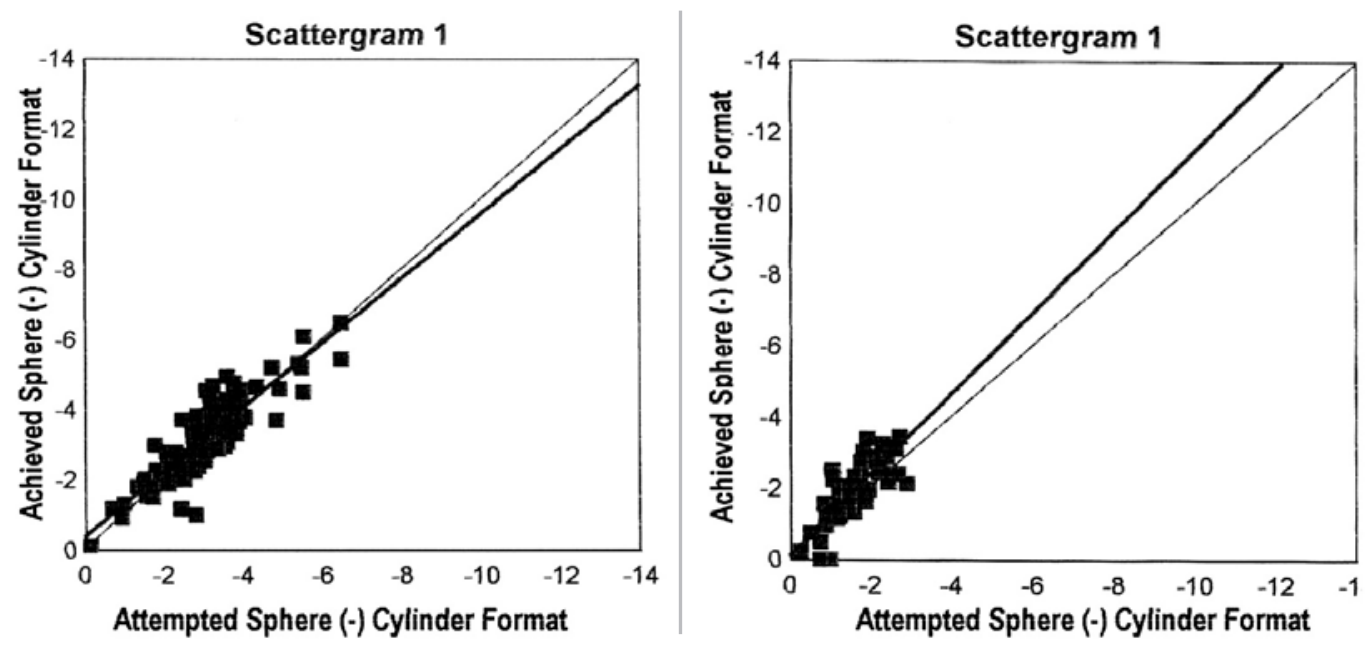

Figure 2. Change Scattergram of attempted vs. achieved spherocylinder refraction of LASIK group (left) and PRK group (right).

cylinder refractive correction in both group. The linear regression slope was positive in the LASIK $(R=0.975, P<0.0005)$ and in the PRK eyes $(R=0.943, P<0.005)$ (Figure 2).

In the LASIK and PRK groups, there were statistically significant changes in the optical aberrations $(P<0.001)$ between preoperative and 1-month postoperative visits, except for the HO RMS $(P=0.16)$ and coma $(P=0.60)$ in the PRK group. From 1-month to 12month postoperative visits, only the spherical aberration showed statistically significant changes in both groups (Figures 3 and 4).

\section{DISCUSSION}

The main goal of our study was to evaluate refractive results of fellow surgeons in-training and variations of induced higherorder aberration in patients treated with wavefront-guided LASIK and PRK, using the same laser system.

Long-term follow-up is an important step in the evaluation of refractive outcomes. The results of 1-year follow-up showed that customized LASIK and PRK procedure was safe, effective and moreover, predictive and stable. 


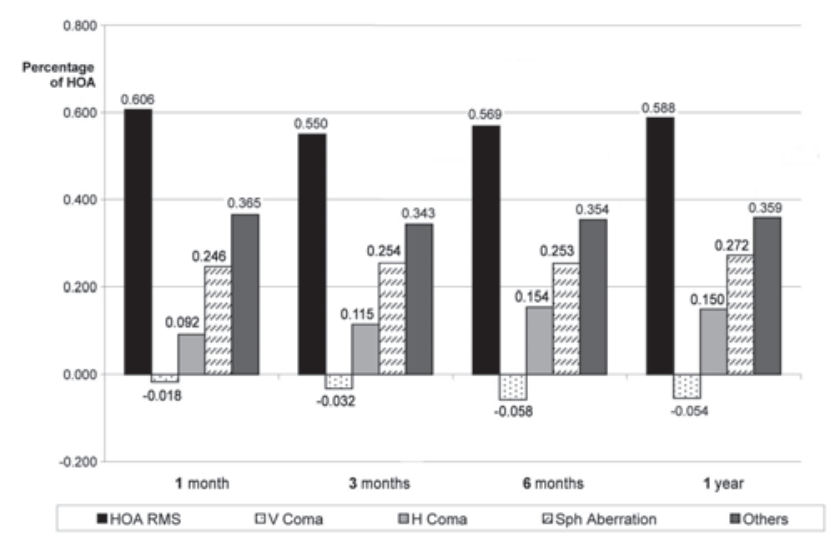

Figure 3. Stability plot of mean higher-order aberrations post LASIK over time.

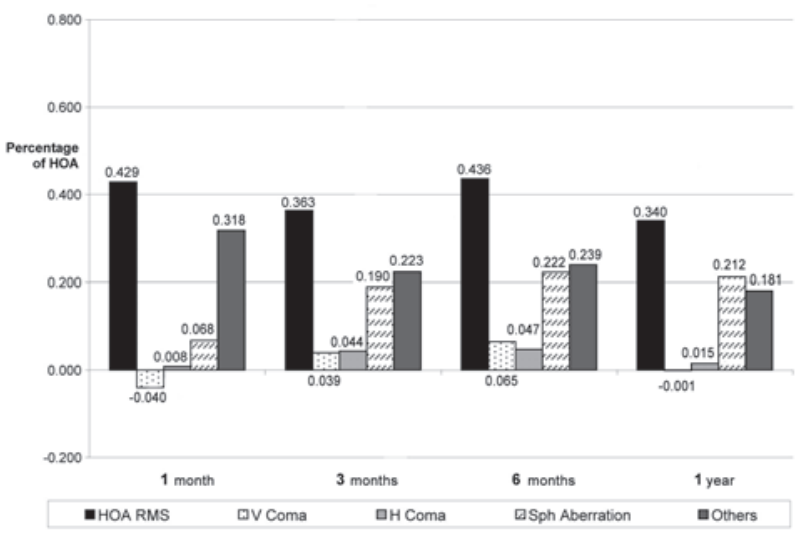

Figure 4. Stability plot of mean higher-order aberrations post PRK over time.

The safety can be measured by the effects on BSCVA. In both groups, no patients lost 2 ou more lines of BSCVA, which is well above as a safe requirement for the Food and Drug Administration $(\text { FDA })^{(13)}$.

Postoperative UCVA and how close the postoperative refraction is to emmetropia are used to determine the efficacy of surgery. The UCVA was 20/40 or better in (100\%) of LASIK group and (91.7\%) in PRK group.

We operated 310 eyes and only 55 completed 1 year followup. Usually, patients who are satisfied with their vision tend not to come back for postoperative visits. These patients who have extended follow-up are those in whom problems may have occurred, thus negatively biasing the values of UCVA.

Our study showed that (80.6\%) (group 1) and (66.7\%) (group 2) were within $\pm 0.5 \mathrm{D}$ of emmetropia at last visit and (93.5\%) (group 1) and (95.8\%) (group 2) within $\pm 1.0 \mathrm{D}$. These values are consistent with the FDA requirements for predictability that require (50\%) within $\pm 0.5 \mathrm{D}$ of emmetropia and (75\%) within $\pm 1.0 \mathrm{D}$.

Correlation between achieved and attempted correction was similar in both groups. Moreover, the achieved correction exceeded attempted correction after each one of the wavefrontguided surgical procedures indicating a tendency to overcorrection.

The retreatment rate is a good indicator of the accuracy of this surgery. Bowers at al. reported that the retreatment rate of resident-performed conventional laser was 3 of 44 eyes (6.8\%). In our study, the retreatment rate of custom laser surgery was 10 of 320 eyes (1.75\%) some related to hipocorrection and flap complications.
In previous studies ${ }^{(14-17)}$ authors have associated the LASIK procedure with a learning curve in which a lower complication rate is seen as more procedures are performed. Al-Swailem, Wagoner ${ }^{(18)}$ founded fellows were significantly more likely to experience microkeratome-related flap complications during their first 25 cases, compared with their second 25 cases (4.8\% vs $1.2 \% ; P=0.03)$. However, there are other studies that demonstrate no correlation among experience, efficacy, and safety ${ }^{(11,19)}$.

In a study looking at the first LASIK surgery performed by 19 newly board-certified ophthalmologists ${ }^{(20)}$, they found that the results were similar to those of experienced surgeons. In that study, (52.6\%) achieved a UCVA of 20/20 or better, (84.2\%) had $20 / 40$ or better, (78.9\%) were within 0.5 D of emmetropia. These results are consistent with our study and strengthen the belief that lack of experience with LASIK surgery does not correlate with a lack of safety and effectiveness if the surgeons are adequately trained. In our study, the fellows performing LASIK and PRK surgeries were always under the supervision and guidance of an attending surgeon.

Some author in order to draw up a kind of learning curve for PRK in the correction of myopia, evaluated the results of 160 consecutive unilateral treatments performed by four surgeons in a multicenter study group, with a one year follow up ${ }^{(17)}$. The mean values for each parameter were calculated by arbitrarily grouping the first 10 cases of each surgeon in the first group (40 patients), the second 10 cases in the second group (40 patients) and so on. They found that increase in UCVA and final refractive error appeared to improve as the surgeon became more experienced, while loss of BSCVA was not significantly influenced by increased surgical experience.

The American Academy of Ophthalmology, evaluating randomized trials comparing LASIK and PRK, found no significant differences in safety and efficacy between the procedures in the treatment of low to moderate myopia at 2 years ${ }^{(21)}$. Both PRK and LASIK were found to be similarly safe, effective and predictable for the correction of low and moderate myopia ${ }^{(22)}$.

Some authors ${ }^{(23)}$ found PRK as a safe and stable surgical procedure to correct myopic refractive errors, with no significant change in mean postoperative spherical equivalent refraction in the long-term follow-up.

Although LASIK has surpassed PRK in popularity because of faster visual recovery, less patient discomfort, and a lower likelihood of significant haze in highly myopic eyes, there are still indications in which PRK is preferred over LASIK. These may include patients with inadequate residual corneal stromal thickness and patients at increase risk for ocular trauma. In addition, higher-order aberrations may be less severe after PRK than after $\operatorname{LASIK}^{(10)}$.

It was showed that wavefront-guided PRK induced a smaller increase of postoperative wavefront-error compared to conventional PRK, particularly in patients with higher preoperative higher-order aberrations ${ }^{(9)}$.

Customized ablation algorithms are devised to cancel existing preoperative aberrations and prevent generation of new aberrations ${ }^{(24)}$.

The last Refractive Surgery Survey 2004 reported that (70.7\%) of respondents observed better results with customized ablation and (67.7\%) were willing to convert back to PRK if it showed better results than wavefront-guided LASIK ${ }^{(12)}$.

We compared our results of customized surgery with results of conventional surgery from literature, performed by training-surgeons (Table 2). We observed that our study showed better refractive outcomes than conventional surgeries. We think that this occurred by one of two reasons: customized surgery can perform more precise ablation or the preoperative refraction is defined more precisaly. 
Table 2. Comparison of refractive outcomes of conventional LASIK and PRK performed by training-surgeons

\begin{tabular}{|c|c|c|c|c|c|}
\hline Author & Follow-up & Total no. of eyes & $\% 20 / 20$ & $\% 20 / 40$ & \pm 0.50 \\
\hline Le Boyer and associates & 1-9 months & 44 & $45.0 \%$ LASIK & $100.0 \%$ LASIK & $71.0 \%$ LASIK \\
\hline Bowers and associates & 1 month & 755 & $77.2 \%$ LASIK & $99.4 \%$ LASIK & $\ldots$ \\
\hline Yo and associates & 2 weeks - 6 months & 52 & $\begin{array}{l}52.6 \% \text { LASIK } \\
40.7 \% \text { PRK }\end{array}$ & $\begin{array}{l}84.2 \% \text { LASIK } \\
96.3 \% \text { PRK }\end{array}$ & $\begin{array}{l}78.9 \% \text { LASIK } \\
54.5 \% \text { PRK }\end{array}$ \\
\hline Stillitano and associates* & 12 months & 310 & $\begin{array}{l}58.1 \% \text { LASIK } \\
66.7 \% \text { PRK }\end{array}$ & $\begin{array}{c}\text { 100.0\% LASIK } \\
\text { 91.7\% PRK }\end{array}$ & $\begin{array}{l}\text { 80.6\% LASIK } \\
66.7 \% \text { PRK }\end{array}$ \\
\hline
\end{tabular}

*= current study

Analysis of total aberrations of the eye represents a direct quantification of retinal image quality, and thus can be related to visual performance ${ }^{(25)}$. Several studies ${ }^{(6,26-27)}$, based on total or corneal surface ablation measurements, have demonstrated that different corneal refractive surgery techniques (PRK, LASIK), although reducing or completely correcting low order aberration (myopia and astigmatism), induce and increase higher order aberration, suggesting a degradation of overall retinal image quality.

Some authors found an increase in higher-order corneal aberrations in both LASIK and PRK, compared to the preoperative values ${ }^{(26)}$. However they did not find differences in Coma-like aberrations between LASIK and PRK. They also report a significant increase in the induction of spherical-like aberrations in the LASIK group.

Different from Oshika et al., our study showed differences in coma aberrations between LASIK and PRK. In PRK-eyes there were not changes in coma. However we observed statistically significant increase of spherical aberration in both groups from 1month to 12-month postoperative visits (wound remodeling) ${ }^{(27)}$.

Collaborating to our results, Wallau et al ${ }^{(28)}$ studying eyes with moderate myopia, also found LASIK eyes induced a greater higher-order aberration $(p=0.01)$ than Mitomicin C-PRK eyes.

Palikaris et al, reported that the creation of a corneal flap induced changes in $3^{\text {rd }}$ - and $4^{\text {th }}$ - order aberrations of the eye. The largest increase was in spherical and coma like aberrations along the horizontal $\operatorname{axis}^{(3)}$.

Similar to Pallikaris et al., in the LASIK eyes, horizontal coma changed from preoperative to 1-month postoperative although remained statistically unchanged during 1-year follow-up. In the other hand, in PRK-group this was not found.

There is an important limitation in our study: the difference in spherical equivalent between groups. The PRK-group included only low myopia. This factor may have led to better results related to higher-order aberrations in this group than in the LASIK-group that included low and moderate myopia.

Our study suggested that with the advancement in instrumentation, the outcome from refractive surgery is becoming less surgeon-dependent and the risk of intraoperative complication can be reduced. We would caution that the study was conducted in an academic setting with direct supervision. Generalize the findings to the community requires further investigation.

The outcome of modern, uncomplicated excimer ablation is remarkable, clearly the impact of higher order aberrations on visual performance is still under investigation.

The evaluation of the results in refractive surgery should include also subjective parameters. This will allow to better correlate the quality-parameters of the surgery to the patient's expectations.

\section{CONCLUSION}

Wavefront-guided LASIK and PRK performed by trainingsurgeons were found to be similarly effective, predictable and stable when the outcomes are compared with outcomes of experienced surgeons. Visual and refractive results did not show any statistically significant difference between the groups and in both groups all patients achieved good UCVA and excelllent BSCVA.

Correlation between expected and achieved correction was similar in both groups and treatment resulted in good efficacy and stability in both groups up to 1 year follow-up.

The achieved refractive correction exceeded attempted correction after each ones of the wavefront-guided surgical proscedures. The HO RMS and coma did not changed signicantly in the PRK eyes from preoperative to 1-year follow-up. In the LASIK eyes the HO RMS and coma changed from preoperative to 1-month postoperative but remained statistically unchanged during 1-year follow-up.

\section{REFERENCES}

1. Mrochen M, Kaemmerer M, Seiler T. Clinical results of wavefront-guided laser in situ keratomileusis 3 months after surgery. J Cataract Refract Surg. 2001;27(2): 201-7.

2. Applegate RA, Thibos LN, Hilmantel G. Optics of aberroscopy and super vision. J Cataract Refract Surg. 2001;27(7):1093-107.

3. Pallikaris IO, Kymionis GD, Panagopoulou SI, Siganos CS, Theodorakis MA, Pallikaris Al. Induced optical aberrations following formation of laser in situ keratomileusis flap. J Cataract Refract Surg. 2002;28:1737-41.

4. Hiatt JA, Grant CN, Wachler Boxer BS. Establishing analysis parameters for spherical aberration after wavefront lasik. Ophthalmology. 2005;6:998-1002.

5. Kohnen T, Buhrer J, Kuhne C, Mirshani A. Wavefront-guided LASIK with the Zyoptix 3.1 system for the correction of myopia and compound myopic astigmatism with 1 year follow-up: clinical outcome and change in higher order aberrations. Ophthalmology. 2004;111(12):2175-85.

6. Seiler T, Kaemmerer, Mierdel P, Krinkle HE. Ocular optical aberrations after photorefractive keratectomy for myopia and myopic astigmatism. Arch Ophthalmol. 2000;118(1):17-21.

7. Aizawa D, Shimizu K, Komatsu M, Ito M, Suzuki M, Ohno K, et al. Clinical outcomes of wavefront-guided laser in situ keratomileusis: 6-month follow-up. J Cataract Refract Surg. 2003;29(8):1507-13

8. Jabbur NS, Kraff C; isx Wavefront Study Group. Wavefront-guided laser in situ keratomileusis using de wave Scan system for correction of low to moderate myopia with astigmatism: 6 months results in 277 eyes. J Cataract Refract Surg. 2005; 31(8):1493-501.

9. Mastropasqua L, Nubile M, Ciancaglini M, Toto L, Ballone E. Prospective randomized comparison of wavefront-guided and conventional photorefractive keratectomy for myopia with the meditec MEL 70 laser. J Refractive Surg. 2004; 20(5):422-31.

10. Panagopoulou SI, Pallikaris IG. Wavefront customized ablations with the WASCA Asclepion workstation. J Refract Surg. 2001;17(5):S608-12.

11. LeBoyer RM, Deutsch TA, Rubenstein JB. Results of resident-performed laser in situ keratomileusis. J Cataract Refract Surg. 2005;31(4):771-5.

12. Sandoval HP, de Castro LE, Vroman DT, Solomon KD. Refractive Surgery Survey 2004. J Cataract Refract Surg. 2005;31(1):221-33.

13. Sanders DR. Matched population comparison of the Visian Implantable collmaer lens and standard LASIK for myopia of - 3.00 to 7.88 diopters. J Refract Surg [Internet]. 2007 [cited 2010 Jun 12]; 23. Available from: http://www.theeyeclinic. com.sg/fileupload/ pdf/20100208034507.pdf

14. Carr JD, Stutling RD, Huang D. Revisiting the LASIK learning curve. Invest Ophthalmol Vis Sci. 1999;40(Suppl):S587.

15. Vidaurri -Leal JS. Complications in 5000 LASIK procedures. Paper presented at: Annual Meeting of American Academy of Ophthalmology. Subspecialty Day. Refractive Surgery: Reshaping the future 1998 Nov 8-11; New Orleans. p.61-4. 
16. Lin RT, Maloney RK. Flap complications associated with lamelar refractive surgery. Am J Ophthalmol. 1999;127(2):129-36.

17. Tavola A, Carones F, Galli L, Fontanella G, Brancato R. The learning curve in myopic photorefractive keratectomy. J Refract Corneal Surg. 1994;10(2 Suppl): S188-93.

18. Al-Swailem SA, Wagoner MD. Complications and visual outcome of LASIK performed by anterior segment fellows vs experienced faculty supervisors. Am J Ophthalmol. 2006;141(1):13-23. Comment in: Am J Ophthalmol. 2006;141(1):143-4.

19. Bowers PJ, Zeldes SS, Price MO, McManis CL, Price FW Jr. Outcomes of laser in situ keratomileusis in a refractive surgery fellowship program. J Refract Surg. 2004 20(3):265-9.

20. Yo C, Vroman C, Ma S, Chao L, McDonnell PJ. Surgical outcomes of photorefractive keratectomy and laser in situ keratomileusis by inexperienced surgeons. J Cataract Refract Surg. 2000;26(4):510-15. Comment in: J Cataract Refract Surg. 2000;26(4):469-70.

21. Sugar A, Rapuano CJ, Culbertson, WW, et al. Laser in situ keratomileusis for myopia and astigmatism: safety and efficacy. A report by the American Academy of Ophthalmology. Ophthalmology. 2002;109(1):175-87.
22. Forseto AS, Nosé RA, Nosé W. PRK versus LASIK para correção de miopia baixa e moderada. Arq Bras Oftalmol. 2000;63(3):257-62

23. Yamazaki ES, Stillitano I Wallau AD, Bottós JM, Campos M. Long-term results of photorefractive keratectomy for myopia and myopic astigmatism. Arq Bras Oftalmol. 2007;70(6):975-80

24. Roberts C. Future challenges to aberration-free ablative procedures. J Refrac Surg. 2000;6(5):S623-9.

25. Schwiegerling J. Theoretical limits to visual performance. Surv Ophthalmol. 2000; 45(2):139-46

26. Oshika T, Miyata K, Tokunaga T, Samejima T, Amano S, Tanaka S, et al. Higher order wavefront aberrations of cornea and magnitude of refractive correction in laser in situ keratomileusis. Ophthalmology. 2002;109(6):1154-8.

27. Oshika T, Klyce SD, Applegate RA, Howland HC. Changes in corneal wavefront aberrations with aging. Invest Ophthalmol Vis Sci. 1999:40(7):1351-5.

28. Wallau AD, Campos M. One-year outcomes of a bilateral randomized prospective clinical trial comparing PRK with mitomycin C and LASIK. Br J Ophthalmol. 2009; 93(12):1634-8.

\section{Simpósio Internacional Moacyr Álvaro - SIMASP}

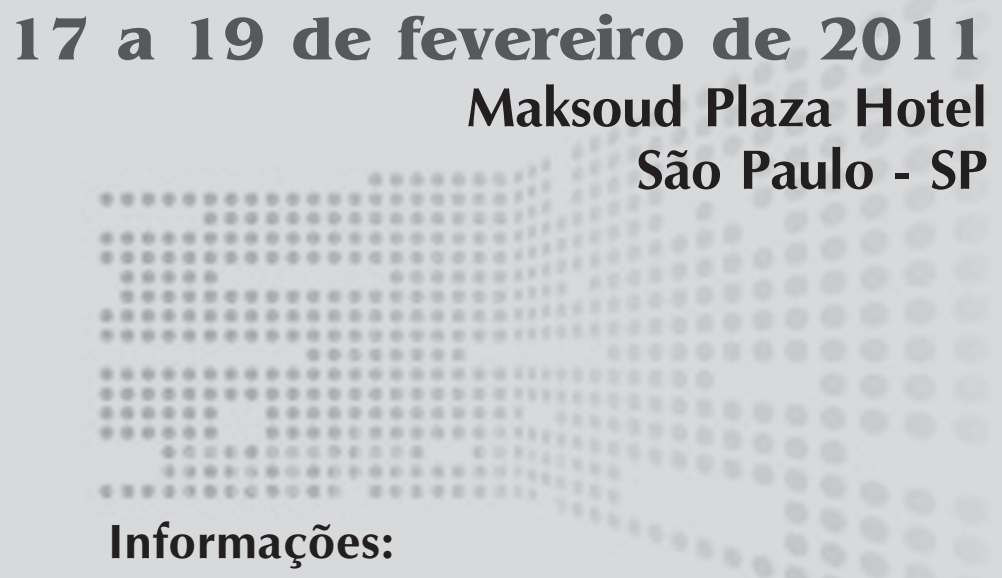

E-mail: ceo@oftalmo.epm.br Site: www.oftalmologiaunifesp.com.br 